\title{
STUDENTS' ERRORS IN USING INFINITIVE AT SECOND YEAR STUDENTS OF SMK SWASTA AWAL KARYA PEMBANGUNAN (AKP) LUBUK PAKAM
}

\author{
Karisma Erikson Tarigan \\ Catholic University of Saint Thomas \\ Email : karisma_tarigan@ust.ac.id
}

\begin{abstract}
This study deals with student's error on the use of Infinitive in written form. The purpose of this study is to find out the type of errors and the causes of errors. This study is carried out at SMK AWAL KARYA PEMBANGUNAN, Jl Pagar Merbau III Lubuk Pakam, to the second year students. There were Forty two students were taken as the sample which taken by cluster sampling technique. The instrument for collecting the data are written test and interview. The result of this study showed that the students made error in using infinitive. The type of errors They were error of addition (854 errors or 73.40\%), error of omission (321 errors or 26.16\%), error of selection (5 errors or 20.43\%). The cause of error Ignore of Rule Restriction (5.73\%), Incomplete Application of Rule (56\%) and False Concept Hypothesized $(37.98 \%)$.
\end{abstract}

Keywords: infinitive, error analysis, error

\section{INTRODUCTION}

\subsection{The Background of the Study}

English plays a very significant role in the process of international communication. Indonesia as a developing country needs to learn more new things from the other countries such as new advance ideas, research findings and experiment. It is undeniable that these things are very important for the national development. English is used in developing countries whose economy, technology and politics are very influential. English mastery, therefore is necessary for every student because they are the agent of change and transformation. In learning English, learners will make errors and mistakes that are natural part of learning process. The learners make errors because they tend to transfer their first language into the target language directly. By analyzing these learners' errors systematically, some information on their competence in the target language can be obtained.

From the statement above, it can be seen that errors in learning a second language are caused by the interference of the learners' mother tongue. In other words, errors made by the learners sometimes are caused by use of the first language.

Making errors are a natural and unavoidable part of the process of learning English. Many kinds of errors arise when the learners do the writing because they do not master the English structure well. Also, errors are the inability of the students in using rules of the components and elements of the second language. Brown (1987: 170) Said that "second language learning is a process that is clearly not unlike first language learning in its trial and errors nature". It means that the learners cannot avoid errors in learning second language. That statement is supported by Wiganti (2000: 11). To limit the discussion that deals with the analysis in this study, this study is to identify the students' errors in using of infinitive and the causes of

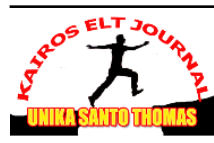


their errors. English has a group of words that resembles verbs and formed verbs, and basic form of verbs called infinitive. By identifying the errors, some problems of grammar can be solved and thus facilitating the comprehension of infinitive in the students' attempt to master English. Based on the explanation above, the writer formulated the problem of the study is What are the causes of the error the students made in using infinitive made by students of SMK Awal Karya Pembangunan?

\section{REVIEW OF LITERATURE}

\subsection{Error}

According to Norish (1983:5) "Error is a mistake deviation from the accepted system of the target language.Mistake is non- systematica deviation from the accepted system of a language being learned and it is usually due to human limitation such as tiredness, nervousness, and fatigue". In addition, Brown (2000:217) states "error is noticeable deviation from the grammar of the native speaker that reflects the competence of the learner, while mistake refers to the performance of the error that is failure to utilize a known system correctly."

\subsubsection{Error Analysis}

Due to the fact that error appears in the learning process, an error analysis is very important. It is intended for finding out the difficulty of learning English as foreign language.

Corder (1989:23) says that "Error analysis is the study and analysis is the study an analysis of the errors made by second and foreign language learner." Error analys is may be carried out in order to : a) finds out how well someone knows the language, b) find out how a person a language, c) obtain information on common difficulties in language learning, as an aid in teaching or in the preposition of teaching materials. Further, Sarma (1989:21) adds that error analysis of student' error with one clear objective: evolving a suitable and effective teaching - learning strategy an remedial measures necessary in certain clearly make out areas of the foreign language. "It is multidimensional and multifaceted process, which involves many more than simply analyzing errors in written or speaking English of learners and counting them for frequency.

\subsubsection{Types of Errors}

Corder in Naibaho (2000:204) divides types of error into four categories. They are Error of Addition, Error of Omission, Error of Selection and Error of Ordering.

\section{Error of Addition}

In using infinitive error of addition was the major error.The error that the students have made were adding word or element that should be omitted.

For example : We can to see the scenery $(\mathrm{F})$

Some students were not aware that after auxiliaries verb, in this case "can" they have to use bare infinitive. The correct answer for this item is "We can see the scenary."

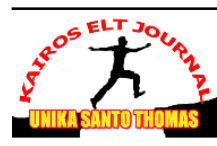




\section{Error of Omission}

The element was omitted which should be presented,it is called error of omission. The students omitted element that made the sentence became imperfect structure.

For example : Many people want see the beach

Some students ommited to form their sentence. They were not aware that "want" should be followed by to infinitive. The correct answer for this item is "Many people want to see the beach.'

\section{Error of Selection}

The wrong item has been choosen in the right place, it is called error of selection.

For example : We will hike in Sinabung for see scenery

Some students made "for" to replace "to" bacause they translate it from bahasa Indonesia. They thought for and to have the same meaning. They were not aware that in infinitive they have to use to.The correct answer for this item is " We will hike in Sinabung to see the scenery."

\section{Error of Ordering}

The students knew that the element was right to be presented but they did not know how to make the sentence perfect structurally.

For example : We wanted to quickly arrive in Berastagi.(F)

It should be : We wanted to arrive in Berastagi quickly.

\subsection{Types of Verb}

The types of verb here differ according to the kind complement they have. Because these types may cut across each other, A verb may belong to more than one type. According to Thomas (1995;370 there are six types or classes of verb. They are transitive, intransitive, ditransitive, intensive verb, complex transitive and prepositional.

\subsubsection{Transitive Verb}

Transitive verb is the kind of verb which is regularly accompanied by direct object. Curme (1993:63) states that transitive verb is a verb that requires an object to complete its meaning. The direct object represent a noun, pronoun, or group of words that tells who or what or what receives or experiences the action of the verb. This type is very numerous. The transitive verb are the only one that may used in passive construction.

If the action or event involves another person or thing, which the action affects to or produces. This is called the object of the verb or clause.

For example :

Jerry put the key

transitive verb direct object

\subsubsection{Intransitive Verb}

When a verb has no object or intensive complement, it is called intransitive. Thomas (1995: 39) states that by contrast, the intransitive verb as its

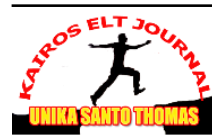


name suggests is a class of verb which does not take an object. The word such as arrive, sleep, cry are intransitive verb.

For example: The girl sleeps

intransitive verb

$$
\text { She was } \frac{\text { crying }}{\text { intransitive verb }}
$$

Sometimes Intransitive verb is followed by the complement. However the presence of complement here is not influenced meaning of the verb.In other words the presence of complement funtioned as optional not as obligatory. For example, He sleeps on the floor. The presence of the complement here is called optional

\subsubsection{Ditransitive Verb}

Another kind verb which occurs with an object is ditransitive (Thomas, 1995:41). However this type of verb, as its name implies two objects. Downing and Philip (2002:85) state that verb which takes two objects, direct and called ditransitive verb. This type of complementation express as situation in which thre e participants are involved, encoded syntactically as the subject and the two objects.

The indirect object typically represents to the person who receives the action or benefits something as a result. While the direct objects identifies the person or thing that is directly affected by the action af the verb. For example in "Reni told the children a story". The children are "and "a story" is " direct object". Some verb that include to this type are give, send, buy, etc.

\subsubsection{Intensive Verb}

Sometimes intensive verb is refferred to linking verb is a verb which does not express only state of being. An intensive verb establish a relationship between the subject and part of predicate. It allows the subject to be identified or modified by complement. Thomas (1955:45) states that intensive verbs belongs to a small group which includes verb like be (most common) seem, appear, become, look and so on.

For examples : He

Johan $\underline{\text { seems }}$

intensive verb

become

intensive verb ill

subject complement

a tennis player subject complement

In each of these examples what is given after the verb relates to the subject, describing their states.Many adjectives can be used as complement.

For examples: Your voice sounds hoarse.

He seems bright.

He feels good today.

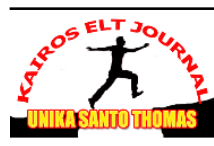


They can modified various ways or have various structures after them.

For examples : Gerald is very happy

Your suspicious are entirely correct

Their hall was larger than his whole flat

Instead of the indirect object in front of the direct object it is possible to put it in prepositional phrase that comes after the direct object.

For example : He showed his driving license to the policeman

She orders a taxi for me

Jack gave a message to Ralph

It is normal to use this prepositional structure when the direct object is pronoun such as "it" or "them".

For examples : I took the glass and gave it to Ana

My brother finished the second page and passed it to the editor.

It is because that pronoun usually refers to things that have already been mentioned, that is the information that is known to your hearer or reader. In English, new information usually comes the end of the clause. So, when the indirect object is new information and the direct object is not. The indirect object is put at the end of the clause.

If we want to put the indirect object in a prepositional phrase, it can be done by using the preposition "to" when the participant is recipient with some verbs. Verbs which take recipient indirect objects and use preposition "to" are typically verbs of transferring goods, services or information from one person to another.

\subsubsection{Complex Transitive Verb}

Complex transitive verb is the kind of verb, which has a complement after their object. Thomas (1995:49) defines that another class of verb which appear with a complement is called complex- transitive. In addition, according to Downing and Philip (2002:93) complex - transitive verb is verbs with one object and an intensive complement. Some transitive verb can have complement after their object. This complement called as the object complement. The object complement is necessary to complete the sentence because it adds information about the direct object and to complete the meaning of the direct object.

\section{RESEARCH METHOD}

This study was a descriptive quantitative approaches. A quantitative approach is defined as a numerical method of describing observation of materials or characteristics. Therefore, descriptive design is a research design which is intended only to describe the variable.

The instrument for collecting data was distinguished into two parts in order to get the result of this study, namely:

1. Written Test

The test was used to figure out the types of errors on the use of infinitive made by students. This study used objective test to obtain data. The test item was completion items, which the first the student were asked by the writer to complete

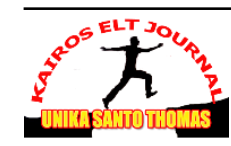


the two different paragraph, the second the students were asked to complete the twenty sentences. The test consisted of 50 items. The test was taken from the textbook. Before administrating the test, the answer sheets would be distributed then the writer wrote the instruction and explained the students how to do the test. The students' seat was arranged in such a way to avoid the students from cheating and the time was allocated 30 minutes for answering the test. After finishing doing the test, the students' answer sheet would be collected.

\section{Interview}

Interview was used to figure out the causes of students' error on the use of infinitive. It is a close interview. Firstly, all the students was asked to get out from the classroom to make the class quite. Secondly, the students were called one by one with pieces of paper. Thirdly, the writer asked the students about the wrong answer that had been answered by the students. Fourthly, analyzed them based on the categories of the causes of error such as : overgeneralization, incomplete application of rules, ignorance of rule restriction, false concept hypothesized or interlingua error. The process of interview was created in such away to make a relax atmosphere so that the students did not feel like being interrogated and the students answered the questions freely without worrying about anything. After all the students' answers in the interview were collected, they were analyzed and classified based on categories of the causes of error.

After collecting the data, the writer then analyzes the students' answer sheets as the following:

a. Identifying the errors by underlining every error from the students' answer sheet.

b. Classifying the errors based on their types

c. Getting the percentage of errors by using formula :

$$
\mathrm{S}=\frac{\mathrm{R}}{\mathrm{N}} \times 100 \%
$$

Where :

$\mathrm{S}=$ Score

$\mathrm{R}=$ The number of the correct answer

$\mathrm{N}=$ The number of the test

\section{DATA ANALYSIS AND DISCUSSION}

\subsection{DATA ANALYSIS}

The total number of error that students made were 1172 errors. There were three types of error made by the students. They were error of addition ( 854 errors or $73.40 \%$ ), error of omission ( 321 errors or $26.16 \%$ ), error of selection (5 errors or $20.43 \%)$. When the errors were viewed from the four types of error, the most dominant error was error of addition (78 errors or $36.3 \%$ ).

These were two causes of error found, they were Interlingua and Intralingua Interference. Interlingua happened when the students transferred their native language system into the target language. While Intralingua happened because of the target language itself due to its complicated system. There were four parts of of Intralingua namely : Overgeneralization, Ignore of rule restriction, Incomplete application of rules and False concept hypothesized. Ignore of Rule 
Restriction (5.73\%), Incomplete Application of Rule (56\%) and False Concept Hypothesized (37.98\%).

\subsection{DISCUSSION}

Having analyzed the data, it was found that students have some problems in using infinitive. It was proven from the data analysis that there were three types of error that students made. They were Error of Addition, error of Omission, error of Selection. The most dominant error was Error of Addition. And there were two causes of error found. They were Interlingua Interference and Intralingua Interference. Intralingua interference can be divided into four categories. They were Overgeneralization, Ignore of rule restriction, Incomplete Application of rules and False Concept Hypothesized. So it indicated that in learning English, infinitive should get an intention ( especially in error of addition as the dominant error) to the English teacher and students. the causes of errors, the sample was interviewed and their responses were transcribed. They were asked on their reason in choosing their incorret choices as the sources of their error. The dominant errors of the students were caused by incomplete application of rules. It shown from the $658(56 \%)$ occurrences of error Incomplete application of rules was a failure to observe the structure whose deviancy represents the degree of development of rules required producing utterance.

\section{CONCLUSION}

It is shown from the $658(56 \%)$ occurrences of error Incomplete application of rules was a failure to observe the structure whose deviancy represents the degree of development of rules required producing utterance. The most dominant error was Error of Addition, There were 854 errors $(73.40 \%)$ error of Addition was made by the students. This error happened because the students added another element or word in the sentence that should be omitted. And there were two causes of error found. They were Interlingua Interference and Intralingua Interference.

\section{BIBLIOGRAPHY}

Cruse, D. Alan.1986. Linguistic Meaning. Oxford: Oxford University Press.

Corder, S.P.1981. Error Analysis And Interlanguage. Oxford: Oxford University Press.

Best, Jhon W and James V.Khan.2002. Research in Education. New Delhi: Prentice-Hall of India.

Brown, H.Douglas. 2000. Principles of Language Learning and Teaching. New York: Addison Wesly Longman.

Curme, O. George. 1993. A grammar of English Language. United States of America.

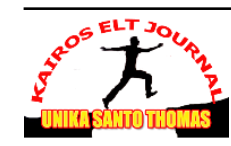


KAIROS ELT JOURNAL, Vol. 3 No. 1 April 2019

Copyright@2019, ISSN: 2580-4278

Downing, Angela \& Philip Locke. 2002. A University Course In English Grammar. Tj Internasional Padsstow Cornwall.

Frank, Marcella.1974. Modern English Grammar Practical Reference Guide.New Jersey : Prentice Hall.

Lou, Robby. 2006. English Grammar and How to Use It. Jakarta: English Plus Series.

Thomas, Linda. 1995. Beginning Syntax. Massachusetts: Blackwell 